\title{
Endoscopic removal of an embedded partially covered esophageal self-expandable metallic stent by overtube technique
}
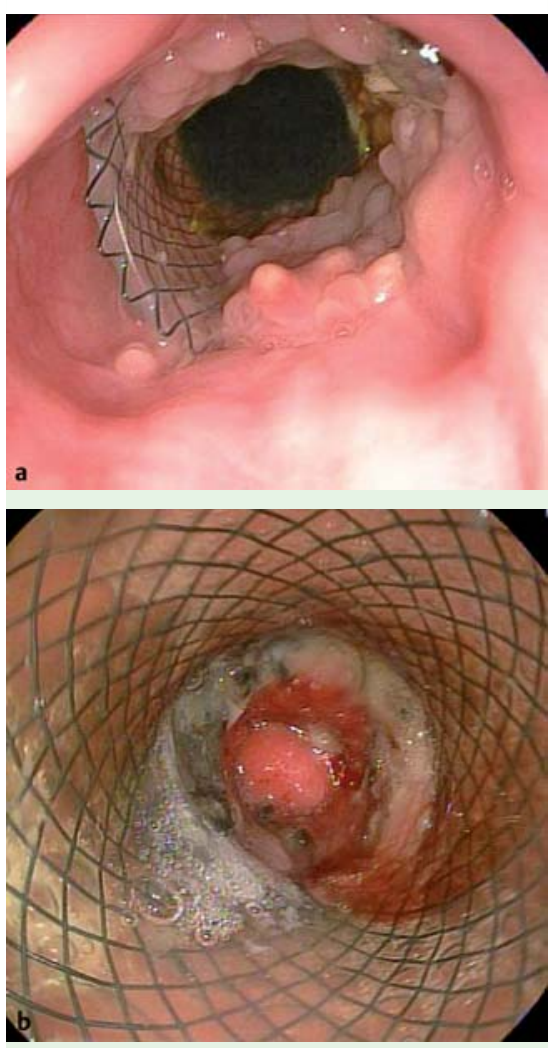

Fig. 1 Endoscopic view showing prominent tissue ingrowth at the proximal (a) and distal (b) uncovered ends of the self-expanding metallic stent (SEMS) in a 48-year-old woman.

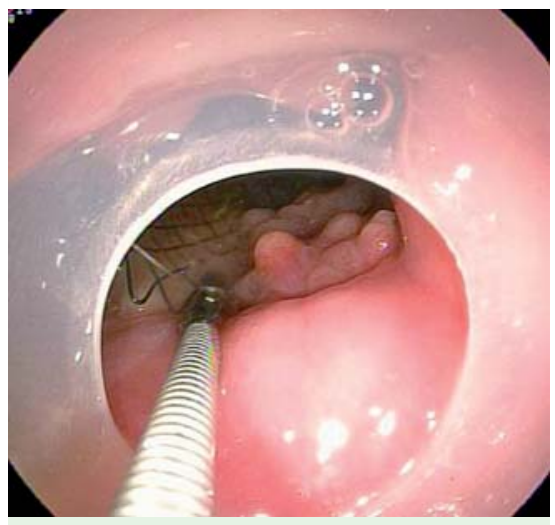

Fig. 3 The uncovered proximal flange of the self-expanding metallic stent (SEMS) was grasped and retracted with biopsy forceps, while pushing down on the overtube.

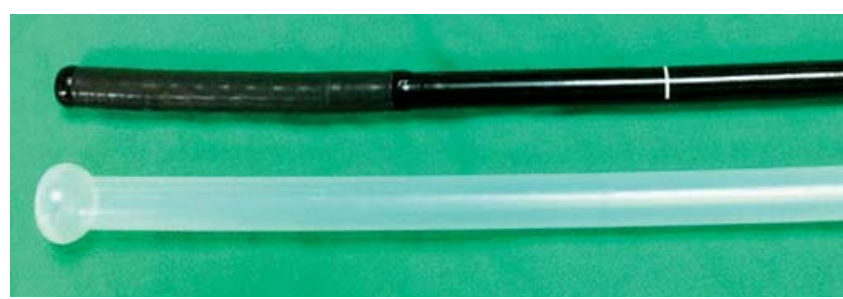

Fig. 2 A standard gastroscope and plastic overtube with ballshaped distal end.

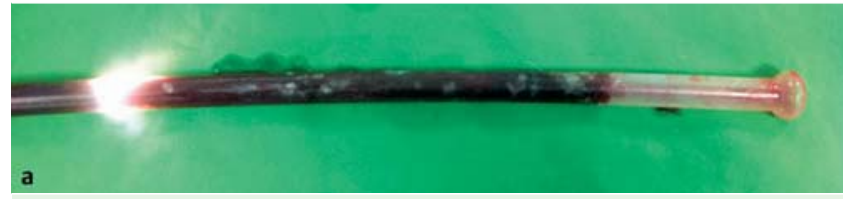

Fig. 4 a The self-expanding metallic stent (SEMS) was successfully retracted into the overtube. The bright area indicates the tip of gas-

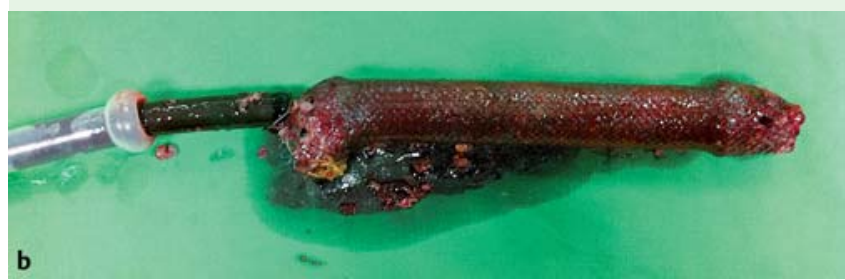
troscope. $\mathbf{b}$ The retrieved self-expanding metallic stent (SEMS).

Self-expandable metallic stents (SEMSs) have been used to treat benign esophageal disorders such as leaks, perforations, and fistulas [1,2]. Fully covered SEMSs are often used to enable stent removal but have the disadvantage of easy dislocation or migration [2]. Stent embedding is a particular problem of partially covered SEMSs and may occur as early as 2-3 weeks after placement [1]. Removal of embedded stents is frequently associated with bleeding and mucosal tears $[3,4]$. We report here the successful retrieval of an embedded partially covered esophageal SEMS by a novel technique involving the use of a plastic overtube.

A 48-year-old woman was referred to our institution for bariatric surgery. Her past medical history was unremarkable and physical examination was normal except for an increased body mass index of $42 \mathrm{~kg} / \mathrm{m}^{2}$. She underwent laparoscopic sleeve gastrectomy, following which she experienced sudden onset of abdominal pain on postoperative day 7. Computed tomography of the abdomen revealed pneumoperitoneum. The patient under- went emergent laparotomy, which revealed a staple line leak near the esophagogastric junction. After 3 weeks following the emergent operation, an esophagocutaneous fistula was seen on a barium esophagogram. A partially covered SEMS (Evolution, $12.5 \mathrm{~cm}$, Cook Endoscopy, Winston-Salem, North Carolina, USA) was placed to compress the esophageal opening of the fistula. Esophagoscopy 5 weeks later showed prominent tissue ingrowth at both uncovered ends of the SEMS ( $\bullet$ Fig. 1). A standard gastroscope and a plastic overtube with ball-shaped distal end and an internal diameter of $9.6 \mathrm{~mm}$ ( $\bullet$ Fig. 2) were used to retract the SEMS. The uncovered proximal flange of the SEMS was grasped and retracted with biopsy forceps, while pushing down on the overtube at the same time ( $\bullet$ Fig. 3 ). The SEMS was successfully retracted into the overtube ( $\bullet$ Fig. 4). and no prominent bleeding or mucosal tear was noted after the procedure.

Endoscopy_UCTN_Code_TTT_1AO_2AZ
Competing interests: None 
S. L. $\operatorname{Yan}^{1,2}$, C. H. Chen ${ }^{1,3}$, Y. H. Yeh ${ }^{1,3}$, S. K. Yueh ${ }^{3}$

1 Division of Gastroenterology, Department of Internal Medicine, Chang Bing Show-Chwan Memorial Hospital, Taiwan

2 Department and Graduate Program of Biolndustry Technology, Dayeh University, Changhua County, Taiwan

3 Division of Gastroenterology, Department of Internal Medicine, Show-Chwan Memorial Hospital, Changhua City, Taiwan

\section{References}

1 Hirdes MM, Siersema PD, Houben MH et al. Stent-in-stent technique for removal of embedded esophageal self-expanding metal stents. Am J Gastroenterol 2011; 106: 286 293

2 Langer FB, Schoppmann SF, Prager G et al. Solving the problem of difficult stent removal due to tissue ingrowth in partially uncovered esophageal self-expanding metal stents. Ann Thorac Surg 2010; 89: 1691 1692

3 Johnsson E, Lundell L, Liedman B. Sealing of esophageal perforation or ruptures with expandable metallic stents: a prospective controlled study on treatment efficacy and limitations. Dis Esophagus 2005; 18: 262-266

4 Wadhwa RP, Kozarek RA, France RE et al. Use of self-expandable metallic stents in benign GI diseases. Gastrointest Endosc 2003; 58: 207-212
Bibliography

DOI $10.1055 / \mathrm{s}-0030-1256945$

Endoscopy 2011; 43: E400 -E401

(c) Georg Thieme Verlag KG Stuttgart · New York . ISSN 0013-726X

\section{Corresponding author}

\section{Y. H. Yeh}

Division of Gastroenterology

Department of Internal Medicine

Chang Bing Show-Chwan Memorial Hospital

No. 6 Lugong Rd

Lugang Township

Changhua County 505

Taiwan

Fax: +886-4-7073226

yslcsmu@hotmail.com 